American Journal of Environmental Sciences 8 (3): 304-310, 2012

ISSN 1553-345X

(C) 2012 Science Publications

\title{
Determining the Effect of Sediment Resuspension from the Activity of Phenoloxidase in Penaeid Shrimp Post Larvae
}

\author{
${ }^{1}$ Napaporn Leadprathom, ${ }^{1}$ Pornpimon Teangtarn, \\ ${ }^{1}$ Kedsiri Ing-Kanorn, ${ }^{2}$ Jayakody A. Sumith and ${ }^{1}$ Molruedee Sonthi \\ ${ }^{1}$ Faculty of Marine Technology, Burapha University, Chanthaburi, 22170, Thailand \\ ${ }^{2}$ Department of Agriculture Peradeniya, Office of the Registrar of Pesticides, Sri Lanka
}

\begin{abstract}
Problem statement: Regular sediment resuspension or dredging in coastal zones can induce stress in a postlaval penaeid shrimp, which affects immune response. Phenoloxidase is a significant enzyme in the penaeid shrimp's immune system which, when used as a biomarker, can serve as an early warning sign in ecological systems. The stress response of shrimp postlarvae from sediment reuspension was analyzed by sediment toxicity test in laboratory. Approach: This study was designed to determine the activity of phenoloxidase with sediment resuspension in two types of postlarval penaeid shrimp, the white shrimp (Penaeus vannamei) (at salinity $17 \mathrm{psu}$ ) and the black tiger shrimp (Penaeus monodon) postlarva 10 (at $17 \mathrm{psu}$ and $3 \mathrm{psu}$ ). Sediment resuspension varied from 1:40, 1:16, 1:8 and 1:4 v/v (sediment/water) and control water (filtered seawater). Sediment in the experiment was taken from Chanthaburi Estuary, Thailand which may contaminated by several pesticides. After resuspension, 20 of the postlarval shrimp were added to one liter of resuspended water for $96 \mathrm{~h}$. At the end of the test, phenoloxidase activity and shrimp survival were analyzed. Results: The study of black tiger shrimp at salinity 3 psu found that only sediment resuspension at 1:40 was sufficient to increase the activity of phenoloxidase in shrimp postlarvae. All sediment resuspension treatments had higher levels of phenoloxidase activity than in the control group. However, only phenoloxidase activity at 1:40 and 1:16 showed a significantly higher difference to the control group $(\mathrm{p}<0.05)$. At $17 \mathrm{psu}$, in both black tiger shrimp and white shrimp, the levels of phenoloxidase activity were higher in sediment resuspension treatments than in the control group. Conclusion: The phenoloxidase activity showed an early response with sediment resuspension even though the response did not show a clear increase in the order of sediment resuspension treatment.
\end{abstract}

Key words: Phenoloxidase activity, penaeid shrimp, sediment resuspension, black tiger shrimp, Analysis of Variance (ANOVA), filtered seawater, test matrix preparation, toxicity tests, dissolve oxygen

\section{INTRODUCTION}

Sediment is both a sink and a source of chemical contaminants in water. The resuspension process usually happens in the dredging process for waterways such as in Chanthaburi Estuary, Thailand, which contains many navigable waterways that require regular maintenance. The area surrounding this estuary contains black tiger shrimp and white shrimp aquaculture and also serves as a nursery ground for shrimp in the postlarval stage (PCD, 2005; Leadprathom et al., 2009). As a consequence, sediment resuspension may expose these aquatic organisms to toxicants. Therefore it is important to determine the effect of this resuspension on aquatic animals.
Phenoloxidase (PO) is an enzyme in crustaceans which occurs after the prophenoloxidase system is stimulated by stress or disease. Phenoloxidase can change phenol to melanin, a chemical which can prevent bacterial growth (Sritunyalucksana and Soderhall, 2000). There are many studies which use PO activity as a biomarker for immune or stress response in Penaeid shrimp, such as the study of PO activity in white shrimp with hydrogen sulfide (Hsu and Chen, 2007). In the latter study, PO activity decreased when shrimp were exposed to hydrogen. Phenoloxidase activity has also been used to investigate the response of Crangon crangon to dredging in a Rotterdam harbor (Smith et al., 1995). 
There were no other study had done or mentioned about the effect of contaminants in the sediment in this area. Therefore, this study attempts to use this enzyme as an early warning biomarker of stress in shrimp caused by sediment resuspension in Chanthaburi Estuary, Thailand, for two different types of shrimp post larvae in laboratory conditions.

\section{MATERIALS AND METHODS}

Sediment sampling: The bottom sediment samples were collected on June 13th, 2007 and June 21st, 2007, from the estuary at the mouth of Chanthaburi River (coordinates UTM48P:1800985 E -13806945 $\mathrm{N})$, in Muang District, Chanthaburi Province, Thailand (Fig. 1). The upper $100 \mathrm{~cm}$ of the sediment samples were taken by SCUBA divers. The cores were manually pushed into the sediment in order to obtain a sample. Within $2 \mathrm{~h}$ of collection, sediment samples were brought into the laboratory and stored at $4^{\circ} \mathrm{C}$. The maximum storage time of sediment before test matrix preparation was less than 1 week.

Shrimp postlarvea sediment toxicity tests: Black tiger shrimp ( $P$. monodon) at postlarva stage 10 were used to test for toxicity using methods which were modified from USEPA (2002). The postlarva shrimp in this study came from commercial hatchery. Briefly, sediment toxicity tests were conducted using sedimentwater combinations at ratios 1:4, 1:8, 1:16, 1:40 and a control of $0: 1$ (vol./vol). The elutriate part of the sediment for each proportion was prepared by mixing sediment with filtered natural seawater for $30 \mathrm{~min}$ and decanting for one hour. One liter of prepared elutriate in each concentration was used to test for toxicity in postlarval shrimp. Triplicate groups of 20 postlarval shrimp were placed in $2 \mathrm{~L}$ small grass aquaria using a static non-renewal system for $96 \mathrm{~h}$.

Measurement of test matrix parameters: Daily measurements of $\mathrm{pH}$, dissolved oxygen and temperature were recorded in each test chamber from 9:00-11:00 am. The actual salinity was measured by using a portable refractometer. Pre- and post experimental, ammonia, nitrite and pre-experimental sulfide were determined using standard colorimetric test methods designed for seawater analysis by Parsons et al. (1984) and unionized ammonia and salinity tables.

Phenoloxidase activity assay: Whole-body macerated hemolymph samples of postlarvae of shrimp were used in the protein and PO assay. The detection of PO activity in a cellular fraction sample was carried out by measurement of L-Dopa transformation in dopachrome (Smith and Soderhall, 1991).

Briefly, $20 \mu \mathrm{L}$ of undiluted hemolymph samples were distributed in a 96 well micro plate Then $30 \mu \mathrm{L}$ of cocodylate buffer (CAC) and $50 \mu \mathrm{L}$ of PO activity modulator (1\% trypsine) were added and the sample was incubated for $10 \mathrm{~min}$ at room temperature. Then $130 \mu \mathrm{L}$ of CAC buffer and $50 \mu \mathrm{L}$ of $5 \mathrm{mM}$ L-Dopa were added. Absorbance was measured at $490 \mathrm{~nm}$ spectrophotometry with VERSAmax tunable microplate reader. The maximum rate of enzyme activity during a 30-min reaction period and measured at 3 min intervals were taken as the basic data input for further calculations. The total protein in matrix samples was assayed by Bradford (1976) protein assay.

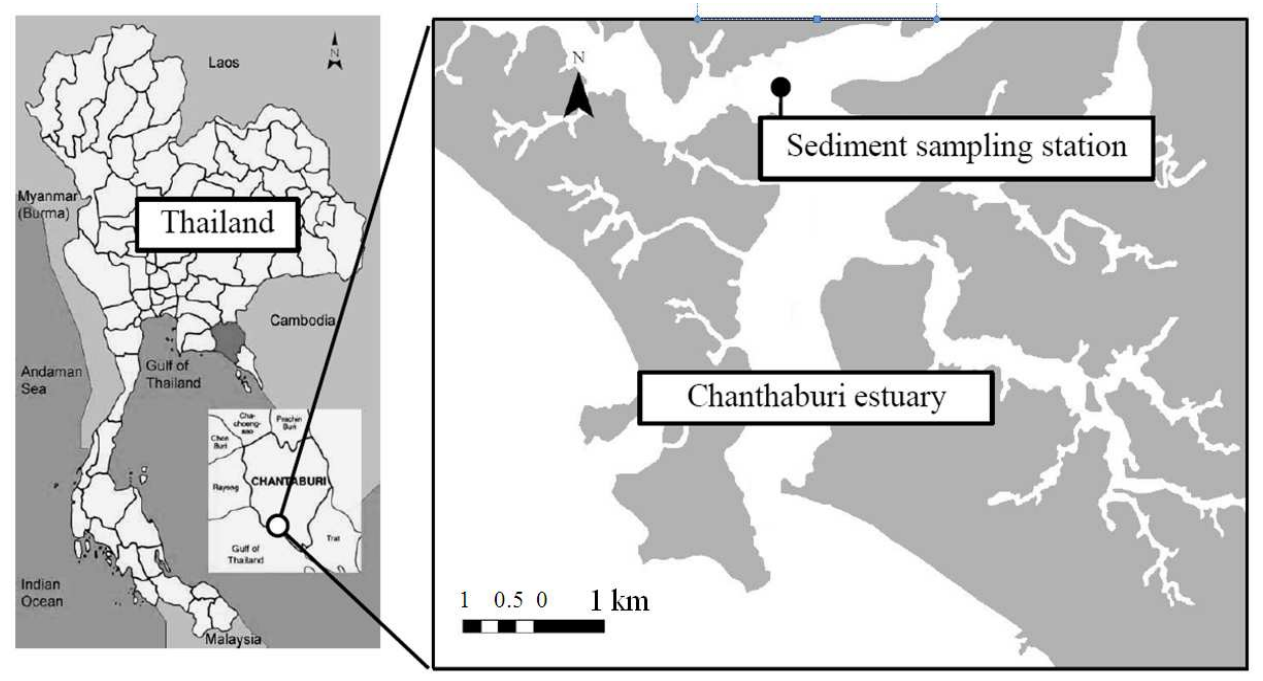

Fig. 1: Sediment sampling station at Chanthaburi estuary Thailand 
At the end of the test, survival and PO activity were analyzed. PO activity in each treatment was compared using Analysis of Variance (ANOVA) and Duncan"s new Multiple Range Test (DMRT). One others tests of white shrimp ( $P$. vannamei) was conducted using postlarva stage 10 . The detail of sediment toxicity tests were similar to those described before, except that the salinity of seawater was 17 psu. The results from two toxicity tests in this study and another one from sediment toxicity test of black tiger shrimp postlarvea at 17 psu by Sumith et al. (2009) were compared.

\section{RESULTS}

After $96 \mathrm{~h}$, the sediment toxicity tests finished and the endpoints for the postlarval shrimps were measured. The observations made are described below.

Water quality: Dissolve oxygen, un-ioninzed ammonia, nitrite, total sulfide and temperature were monitored in sediment toxicity test. The result showed that all of parameters were within safety level for aquatic animal except un-ionized ammonia which slightly hihger than safety level (Table 1).

Postlarval shrimp survival: The survival rate of exposed shrimp at $96 \mathrm{~h}$ in the three tests ranged from 63.3-93.2 \% (Table 2). In black tiger shrimp at 3 and 17 psu salinity; the survival in sediment resuspension treatments were nearly the same as in the control groups. In the white shrimp test, the survival in exposed shrimp was slightly less than the control group. However, the mortality did not increase in order of sediment resuspension. This indicates that sediment resuspension did not influence shrimp mortality.

Phenoloxidase activity: At 3 psu, PO activity in black tiger shrimp postlarvea in all sediment elutriate treatments (1:40, 1:16, 1:8 and1:4) were higher than the control group. Activity rates were $276 \pm 44,276 \pm 34$, $193 \pm 16$ and $201 \pm 65$ unit/min/mg protein respectively. Meanwhile the activity in control group was 150.2 \pm 62.5 (Fig. 2a). However, only PO activity of shrimp at 1:40 and 1:16 elutriate was significantly different than the control group (Fig. 2a) $(\mathrm{p}<0.05)$. Similarly, PO activity in white shrimp and black tiger shrimp at 17 psu (Sumith et al., 2009) also found increased PO activity in shrimp which were exposed to elutriate.. The levels of $\mathrm{PO}$ activity in black tiger shrimp at $17 \mathrm{psu}$ in control, 1:40, 1:16, 1:8 and1:4 were $72 \pm 43,71 \pm 23,80 \pm 14,92 \pm 75$ and $72 \pm 15 \mathrm{unit} / \mathrm{min} / \mathrm{mg}$ protein, respectively (Fig. 2b). In addition, the level of PO in white shrimp at $17 \mathrm{psu}$ in control, 1:40, 1:16, $1: 8$ and $1: 4$ were $112 \pm 36,152 \pm 24,133 \pm 20,168 \pm 14$ and $133 \pm 23 \mathrm{unit} / \mathrm{min} / \mathrm{mg}$ protein, respectively (Fig. 2c). However, PO activity in both tests was not significantly different between control treatment and elutriate treatments $(\mathrm{p}>0.05)$.

Relative change of PO activity: The level of PO activity was normalized based on the level of PO activity of shrimp in the control group in each experiment. The PO activity level in each sediment resuspension group is shown as an increasing or decreasing percentage compared with the control group (Fig. 3). The results show that most PO activity in postlarval shrimp which were exposed to elutriate increased, particularly in black tiger shrimp.

Table 1: Water quality in shrimp postlarvea toxicity tests

\begin{tabular}{|c|c|c|c|c|}
\hline Parameter & Black tiger shrimp3 psu & Black tiger shrimp 17 psu & White shrimp $17 \mathrm{psu}$ & Safety level for aquatic animal \\
\hline Dissolve oxygen (mg/L) & $4.27-6.15$ & $4.30-5.45$ & $4.82-4.99$ & - \\
\hline Un-ioninized ammonia (mgN/L) & nd-0.03 & nd-0.03 & $0.005-0.09$ & $<0.02$ Lawson $(1995)$ \\
\hline Nitrite $(\mathrm{mgN} / \mathrm{L})$ & $0.09-0.19$ & $0.009-0.06$ & $0.001-0.007$ & $<0.1$ Lawson $(1995)$ \\
\hline Total sulfide $(\mathrm{mgS} / \mathrm{L})$ & nd & nd & nd & $<0.003$ Macdonald (2000) \\
\hline Temperature $\left({ }^{\circ} \mathrm{C}\right)$ & $26.5-28.9$ & $26.7-28.8$ & $27.6-28.0$ & - \\
\hline
\end{tabular}

Table 2: Survival of shrimp postlarvea in sediment toxicity tests

\begin{tabular}{llll}
\hline & Shrimp postlarvea survival (\%) means (range) & \\
Group of experiment & Black tiger shrimp 3 psu & Black tiger shrimp 17 psu & White shrimp 17 psu \\
\hline Control & $80.0(75.0-85.0)$ & $86.3(80.0-85.0)$ & $85.0(80.0-90.0)$ \\
$1: 40$ & $78.3(80-85)$ & $81.7(75.0-85.0)$ & $63.3(85.0-90.0)$ \\
$1: 16$ & $76.7(60-75)$ & $82.4(75.0-85.0)$ & $70.0(60.0-90.0)$ \\
$1: 08$ & $80.0(70-85)$ & $93.2(90.0-95.0)$ & $70.0(60.0-90.0)$ \\
$1: 04$ & $63.3(60-80)$ & $80.0(75.0-90.0)$ & $76.7(75.0-80.0)$ \\
\hline
\end{tabular}


Am. J. Environ. Sci., 8 (3): 304-310, 2012

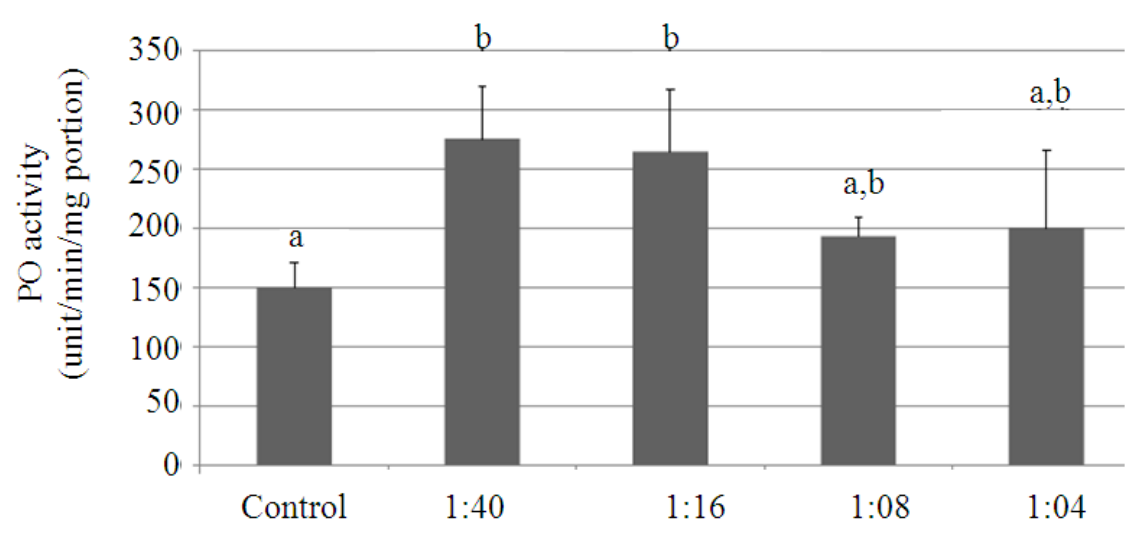

Proportion of sediment: water

(a)

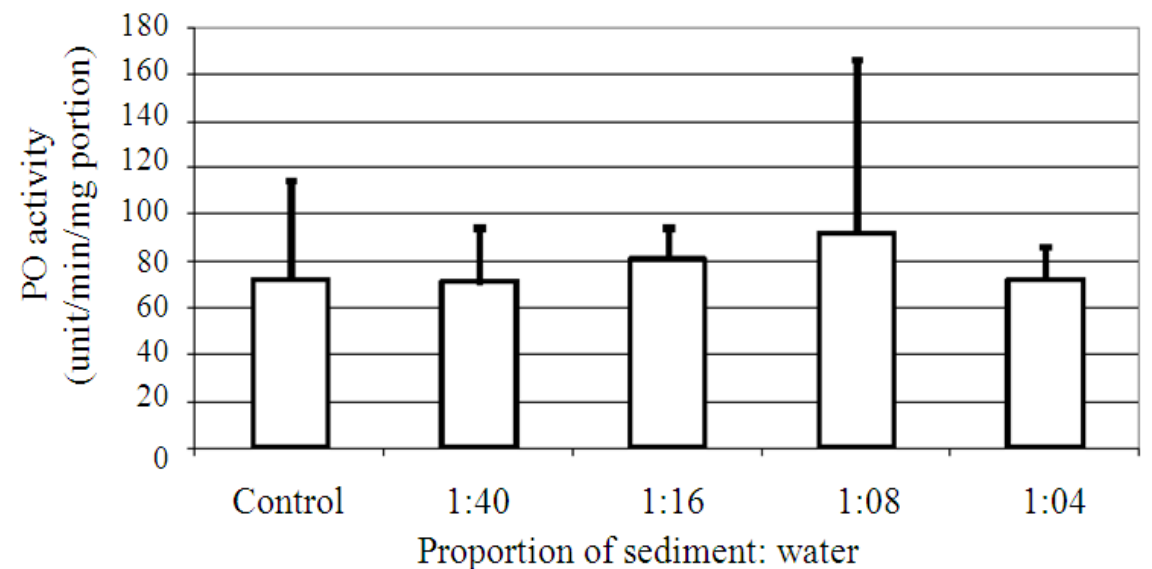

(b)

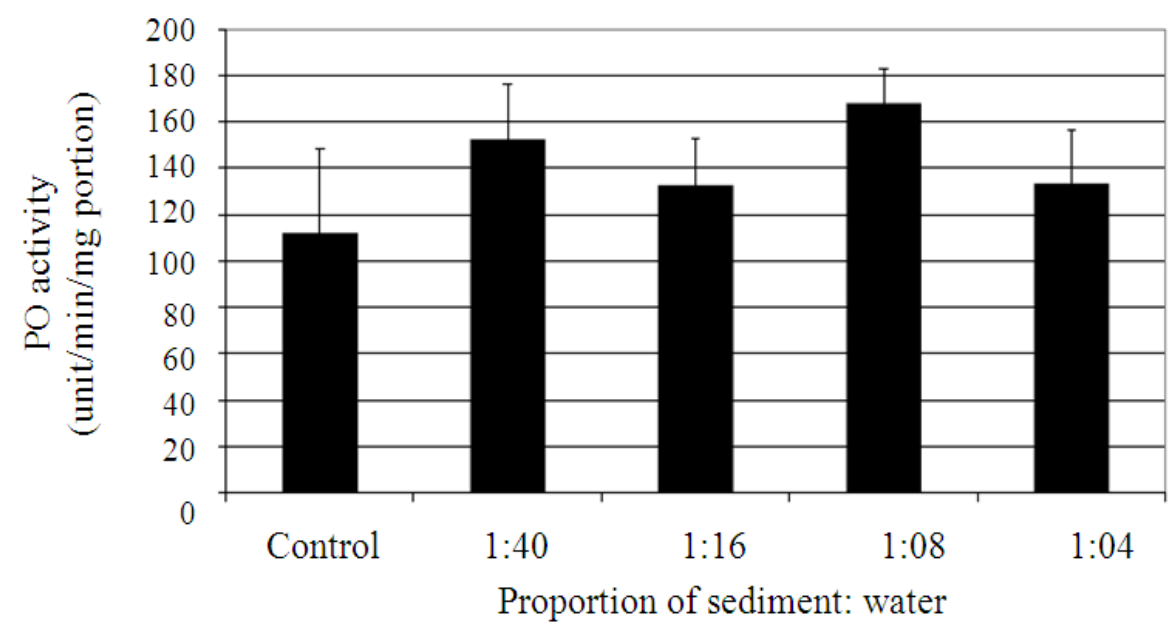

(c)

Fig. 2: Phenoloxidase activity response in shrimp toxicity test Mean \pm SD (a) Black tiger shrimps at 3 psu (b) Black tiger shrimp at 17 psu (Sumith et al., 2009) (c) White shrimp at 17 psu 


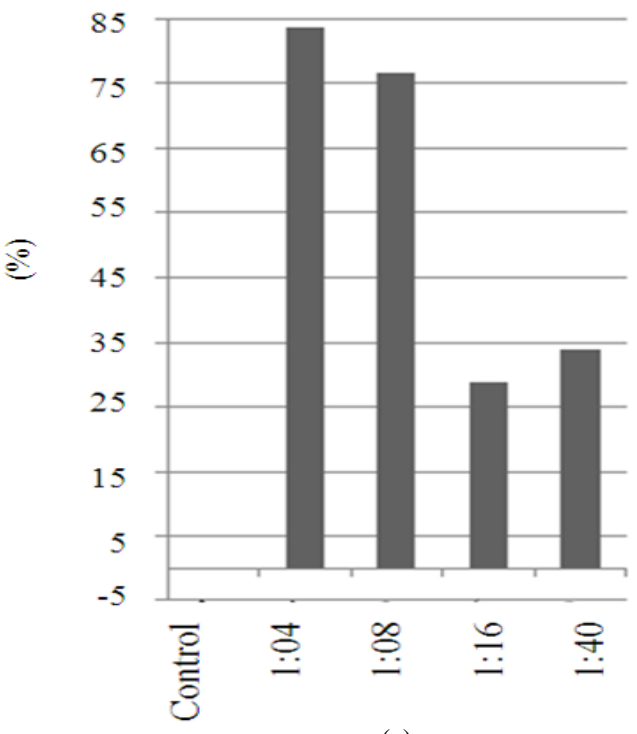

(a)

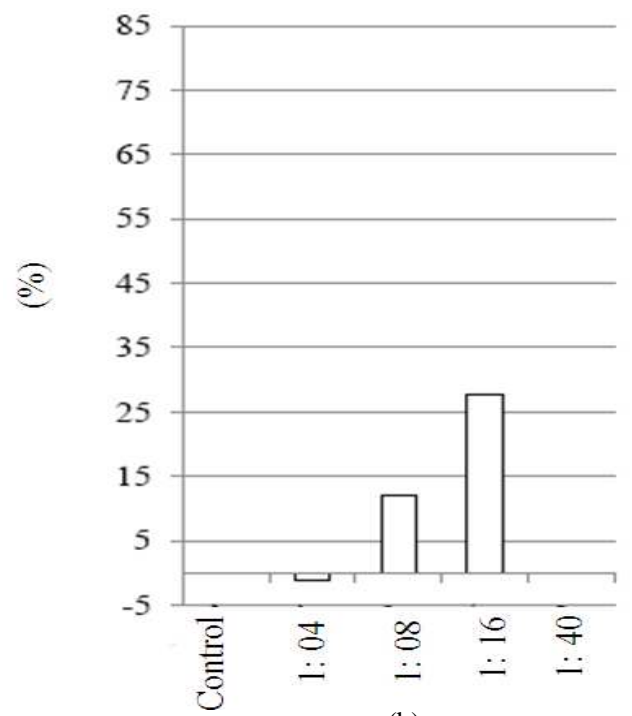

(b)

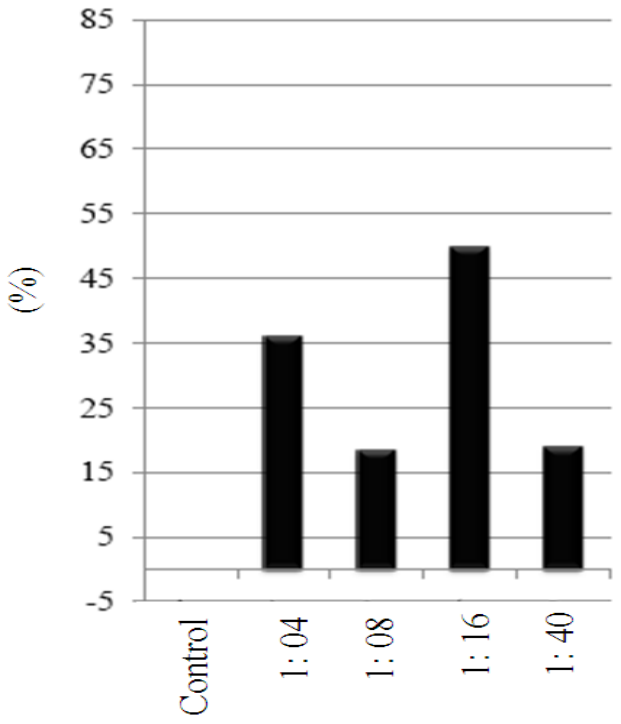

(c)

Fig. 3: Comparison phenoloxidase activity (\%) against control group in shrimp postlarvea toxicity test (a) Black tiger shrimp 3 psu (\%) (b) Black tiger shrimp 17 psu (\%) (c) White shrimp 17 psu (\%)

Compared with the PO activity of shrimp in different salinities, the PO activity of shrimp in 3 psu (2790\%) have a higher response than black tiger shrimp in $17 \mathrm{psu}(-2-27 \%)$. This may indicate that shrimp in $3 \mathrm{psu}$ have a stronger reaction to the effects of sediment resuspension than shrimp in higher salinities.

Moreover, the results from the white shrimp postlarvae test show that $\mathrm{PO}$ activity response (17-50\%) in the test had higher PO activity than black tiger shrimp at 17 psu.

\section{DISCUSSION}

The sediment resuspension did not show a clear effect on shrimp mortality. Meanwhile, the PO activity increased in almost all shrimp which were exposed to elutriate sediment. This finding indicates that PO activity shows an early response before the most severe effect, such as mortality, occurs. This is similar to the results of study in Crangon crangon in which PO activity shows an early response (Smith et al., 1995). 
However, the response pattern of this study was different from the Smith et al. (1995) and Hsu and Chen, 2007) studies, which showed a decreasing trend of PO activity with increasing concentration of contaminants which are hydrogen sulfide and PCBs. This difference may be due to different sources of pollution in the sediment. Hsu and Chen (2007) study, for example, Hydrogen sulfide was the main pollutant, while in the Chanthaburi Estuary area many pesticides have been reported in the sediment, such as $\mathrm{HCHs}$, endosulfan, paraquat and glyphosate (Leadprathom et al., 2009; Totong, 2010). This finding indicated that PO activity in shrimp postlarva may be use as early warning biomarker for chemical hazard. However, PO activity is less specific biomarker because PO activity showed response to several contaminants (Smith et al., 1995; Hsu and Chen, 2007).

Comparing PO activity normalized by the control group's activity level, postlarval shrimp in low salinity show a higher effect than postlarval shrimp in higher salinity. Salinity has many effects on pollutants in water; for example, some heavy metals such as copper and cadmium are highly toxic in low salinity (Coglianese, 1982; Voyer and Modica, 1990). Therefore it is possible that in Chanthaburi Estuary, sediment may have pollutants which are more toxic in low salinity.

In addition, the PO activity level is higher in white shrimp than in black tiger shrimp. Black tiger shrimp is a native Thai species while white shrimp is an invasive species which was introduced for aquaculture purpose (Briggs, 2005). Thus, it is possible that native species like black tiger shrimp may tolerate the sediment resuspension better than white shrimp of the same age.

\section{CONCLUSION}

Exposing postlarval shrimp to sediment resuspensions lead to increased PO activity, making it useful as an early warning biomarker. However the pattern of response was not clear. It did not increase in order of sediment resuspension and increased PO activity did not always show a readily observed adverse effect on the test species. Therefore other endpoints such as physiological change and histological observation need further investigation to validate these test results. Also, measures of contaminants in sediment ingredients for both controls and field-collected sediments should be made in future studies.

The results of the shrimp toxicity tests in this study can be used to manage risks to aquatic animals in the area. For example, dredging should be conducted at a higher salinity rate, because these test results show a lower response of PO activity at the higher salinity rate.

\section{ACKNOWLEDGEMENT}

Reaearchers are grateful to the Faculty of Marine Technology, Burapha University Thailand for providing financial support. Sincere appreciations are extended to Dr. Prapasiri Barnette Department of Aquatic Science, Burapha University, who provided facilities to conduct immunological experiments in her laboratories.

\section{REFERENCES}

Bradford, M.M.A., 1976. A rapid and sensitive method for the quantitation of microgram quantities of protein utilizing the principle of protein-dye binding. Anal Biochem., 72: 248-54. PMID: 942051

Briggs, M., 2005. Introductions and Movement of Two Penaeid Shrimp Species in Asia and the Pacific. 1st Edn., Food and Agriculture Organization, Rome, ISBN-10: 9251053626, pp: 78.

Coglianese, M.P., 1982. The effects of salinity on copper and silver toxicity to embryos of the Pacific oyster. Arch. Environ. Contain. Toxicol., 11: 297303. PMID: 7103561

Hsu, S.W. and J.C. Chen, 2007. The immune response of white shrimp Penaeus vannamei and its susceptibility to Vibrio alginolyticus under sulfide stress. Aquaculture, 271: 61-69. DOI: 10.1016/j.aquaculture.2007.05.028

Lawson, T.B., 1995. Fundamentals of Aquaculture Engineering. 1st Edn., Chapman and Hall, New York, ISBN-10: 0412065118 pp: 355.

Leadprathom, N. P. Parkpian, J. Satayavivad, R.D. Delaune and A. Jugsujinda, 2009. Transport and deposition of organochlorine pesticides from farmland to estuary under tropical regime and their potential risk to aquatic biota. J. Environ. Sci. Health, Part B, 44: 249-261. PMID: 19280478

MacDonald, D.D., 2000. A Compendium of Environmental Quality Benchmarks. 1st Edn., Georgia Basin Ecosystem Initiative, Vancouver.

PCD, 2005. Marine pollution and mitigation mearsure in Thailand. Marine Environment Division, Pollution Control Department, Thailand,

Parsons, T.R., Y. Maita and C.M. Lalli, 1984. A Manual of Chemical and Biological Methods for Seawater Analysis. 1st Edn., Pergamon Press, Oxford, ISBN-10: 0080302882 pp: 173.

Smith, V.J. and K. Soderhall, 1991. A comparison of phenoloxidase activity in the blood of marine invertebrates. Dev. Comp. Immunol., 5: 251-261. PMID: 1773850 
Smith, V.J., R.J. Swindlehurst, P.A. Johnston and A.D. Vethaak, 1995. Disturbance of host defence capability in the common shrimp, Crangon crangon, by exposure to harbor dredge spoils. Aquatic Toxicol., 32: 43-58. DOI: 10.1016/0166445X(94)00078-5

Sritunyalucksana, K. and K. Soderhall, 2000. The proPO and clotting system in crustacean. Aquacuture, 191: 53-69.

Sumith, J.A., P. Parkpian and N. Leadprathom, 2009. Dredging influenced sediment toxicity of endosulfan and lindane on black tiger shrimp (Penaeus monodon Fribricus) in Chanthaburi River estuary Thailand. Int. J. Sediment Res., 24: 455464. DOI: 10.1016/S1001-6279(10)60017-0
Totong, K., 2010. Ekokinetics of herbicides from farmland to the river: A case study at the Chanthaburi estuary Thailand. Master Thesis, Asian Institute of Technology, Thailand.

USEPA, 2002. Methods for measuring the acute toxicity of effluents and receiving waters to freshwater and marine organisms. United States Environmental Protection Agency.

Voyer, R.A. and G. Modica, 1990. Influence of salinity and temperature on acute toxicity of cadmium to Mysidopsis bahia Molenock. Arch. Environ. Contain. Toxicol., 19: 124-131. PMID: 2331146 